\title{
ANALYSIS OF MUSCULOSKELETAL SYMPTOMS (PAIN) AND CHARACTERISTICS OF THE ANTHROPOMETRIC PARAMETERS IN THE MILITARY PERSONNEL
}

\author{
Liana Pl̦avin̦a ${ }^{1}$, Silvija UmbrašKo ${ }^{2}$ \\ ${ }^{1}$ National Defence Academy of Latvia, Riga, Latvia \\ 2 Institute of Anatomy and Anthropology, Department of Morphology, \\ Riga Stradins University, Riga, Latvia
}

\begin{abstract}
Musculoskeletal disorders are connected to external and internal factors. External conditions in the military environment are characterized with a high physical load and psychological load. Internal factors are connect to individual health capacity, anthropometric characteristics, posture and foot state or the deviation from the standard. The pain is a common subjective sign of musculoskeletal pathology. The pain symptoms could be the initial symptom of musculoskeletal pathology which is an important cause of morbidity in the military service $[6,7]$. The nature of the musculoskeletal problems suggests that a combination of ergonomic and individual/organizational intrinsic and extrinsic factors are associated with the military environment. We have provided for the analysis of cadets of the national Defence Academy in the period 2013-2014 the anthropometric parameters, the calculation of the body fat range according to the Guidelines of WHO and the data of the standardized Nordic Questionnaire for the Analysis Musculoskeletal Symptoms. The analysis of the average value of the body mass index fixed differences between the respondents' groups. The assessment of the range of the body mass index revealed that the number of the individuals related to the overweight problems increased with the age about 1.5 times. Evaluations of the body fat range have shown that the number of the individuals with the healthy assessment of the body fat range decreased about two times with the age. Military training conditions with the combination of the intrinsic (individual) factors form the risk for musculoskeletal disorders. The most common problematic areas of pain are the lower back region, the hip joint region, the knee joint region, but the largest problem is the combined pain for the lower back and the knee joint
\end{abstract}


region. The analysis of anthropometric parameters and evaluation of data Questionnaire for Analysis Musculoskeletal Symptoms may be important to provide preventive measures to reduce the risk of musculoskeletal disorders linked to a specific job and the treatment at the early stage where the combination of the extrinsic factors condition and intrinsic factors is present.

Keywords: anthropometric characteristics of the military personnel, posture assessment of the military personnel

\section{INTRODUCTION}

Musculoskeletal disorders are connected to external and internal factors. External conditions in the military environment are characterized with a high physical load and a psychological load. Physical endurance for the military personnel is checked up annually by standardized physical tests (cross country race $3000 \mathrm{~m}$, push-up tests and a sit-ups test). Internal factors are connected to individual health capacity, anthropometric characteristics, posture and foot state or the deviation from the standard. The pain is a common subjective sign of musculoskeletal pathology [8]. The pain symptoms could be the initial symptom of musculoskeletal pathology which is an important cause of morbidity in the military service $[5,6,9]$. Finnish $[11,12]$ Norwegian, Swedish [2], Danish Defence Force [5, 6], the US Army [1,3] epidemiological studies have shown that pain symptoms are important for physically active conscripts, a significant number of training days is lost due to musculoskeletal disorders. The most important pain areas are those of lumbar spine (cervical and lumbar portion), and lower extremities. The nature of the musculoskeletal problems suggests that a combination of ergonomic and individual/organizational intrinsic and extrinsic factors associated to the military environment as well as psychosocial factors may play a role in the development, exacerbation and the maintenance of work disability in the military population Often musculoskeletal pain affects the daily activities of the patient.

\section{MATERIAL AND METHODS}

We have provided for the analysis of cadets of the national Defence Academy in the period 2013-2014 the anthropometric parameters, the calculation of the body fat range according to the Guidelines of the WHO [4] and the data of the standardized Nordic Questionnaire for the Analysis of Musculoskeletal Symptoms [7]. There were four groups of respondents: the 1st experimental group 
included 1st year cadets (2013) in the age of 19-21 years, $n=35$; the 2 nd experimental group included the 1st year cadets (2014) in the age of 19-21 years, $\mathrm{n}=34$; the 3 rd experimental group included the 4 th year cadets (2014) in the age of $21-30,(n=16)$, the 4 th experimental group included the 5 th year cadets (2014) in the age of 23-28 years, $n=15$. The foot and the posture statements were analysed in the Anthropology Laboratory of the Institute of Anatomy and Anthropology of Riga Stradins University for one group of cadets (the 4th experimental group for 5 th year cadets (2014).

\section{RESULTS AND DISCUSSION}

The military person should have a high physical fitness level and health capacity of the standard level. Cadets of the National Defence Academy have passed through recruiting procedures to the National Armed Forces that include various check-up - control stages: the health capacity evaluation according to the regulation, physical tests. The studies in the National Defence Academy are characterized with a high physical load, an intensive training process. We provide the assessment of the anthropometric characteristics in the 1st group of cadets in the 1st year (2013). The average Body Mass Index (BMI) in the 1st group was $24.9 \pm 0.4$. For the $57.1 \%$ of cadets the BMI value corresponded to the standard level ( $18.0-24.9$ ), but for $34.3 \%$ of the cadets the BMI value were in the interval of overweight (25.0-29.9) and for the $8.6 \%$ of cadets the BMI value is above 30 that related to the obese range (Figure 1). We have calculated the body fat range for the cadets of the 1st year (2013) and revealed the fact that $77.1 \%$ of cadets have the evaluation of the healthy body fat range, but $17.1 \%$ of respondents of the 1 st experimental group had the evaluation over the fat range. The $5.7 \%$ of the 1st year cadets have the body fat range that corresponded to the obese range (Figure 2). According to our data for $1 / 5$ of the cadets in the 1st year (2013) the body fat range was above the standard level that increased the risk of the health problems, musculoskeletal disorders. The analysis of musculoskeletal symptoms according to the standardized Nordic Questionnaire for the 1st year cadets (2013) revealed that more than $80 \%$ of respondents in the 1st group $(\mathrm{N}=35,2013)$ have musculoskeletal troubles (Figure 3$)$. The pain in the low back region (62.1\%) was the principal problem in that group. The second expressed musculoskeletal symptom region was the knees region (37.8\%). The pain symptoms combined in the lower back region, the hip joint and the knee joint. The isolated pain disorders in the lower back region were had by $20 \%$ of respondents, but combined pain symptoms in the 
lower back region and in the knee joint pointed out $34.3 \%$ of respondents; the combined pain symptoms in the lower back region and the hip joint were had by $8.54 \%$ of cadets and $5.7 \%$ have the combined pain in the lower back region, the hip joint, the knee joint.

The evaluation of the anthropometric data in the 2nd group for the 1st year cadets (2014) show the same situation concerning the anthropometric char-

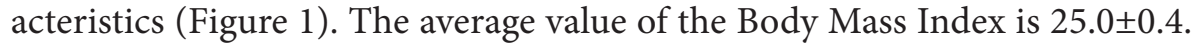
The $64.7 \%$ of the 1 st year cadets (2014) have the BMI in the standard interval from $18.0-24.9$. The data of the BMI for $35.3 \%$ of cadets were in the interval from 25.0 till 29.9 that related to the overweight problems. The $2.9 \%$ of the 1 st year cadets (2014) have the obese range that is two times than in the previous group (the1st group of cadets the 1st year (2013). The body fat range for $91.2 \%$ of cadets in the 2 nd group corresponds to the healthy range, but $11.8 \%$ of cadets have fixed problems of fat (Figure 2). The assessment of the questionnaire data concerning the musculoskeletal symptoms for the 2nd group of cadets $(n=34,2014)$ revealed that musculoskeletal pain symptoms are found in $75 \%$ of respondents. The $39.4 \%$ of respondents have troubles in the lower back, $30.3 \%$ in the shoulder region and $27.3 \%$ in the knee region. The isolated pain in the lower back region was in $17.6 \%$ of cadets (Figure 3), but combined pain disorders are had by $17.6 \%$ of cadets, only some of the cadets, have combined pain in the lower back region and the hip joint $(2.9 \%)$ and the combined pain in three regions (lower back, hip joint and knee joint).

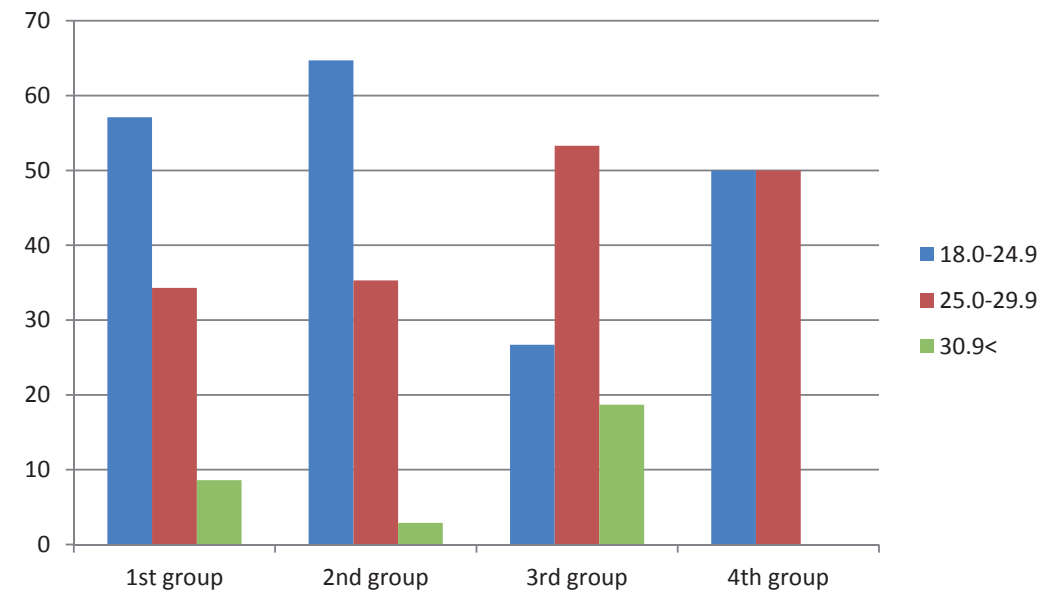

Figure 1. Body mass index distribution in the experimental groups of cadets of NDA. 


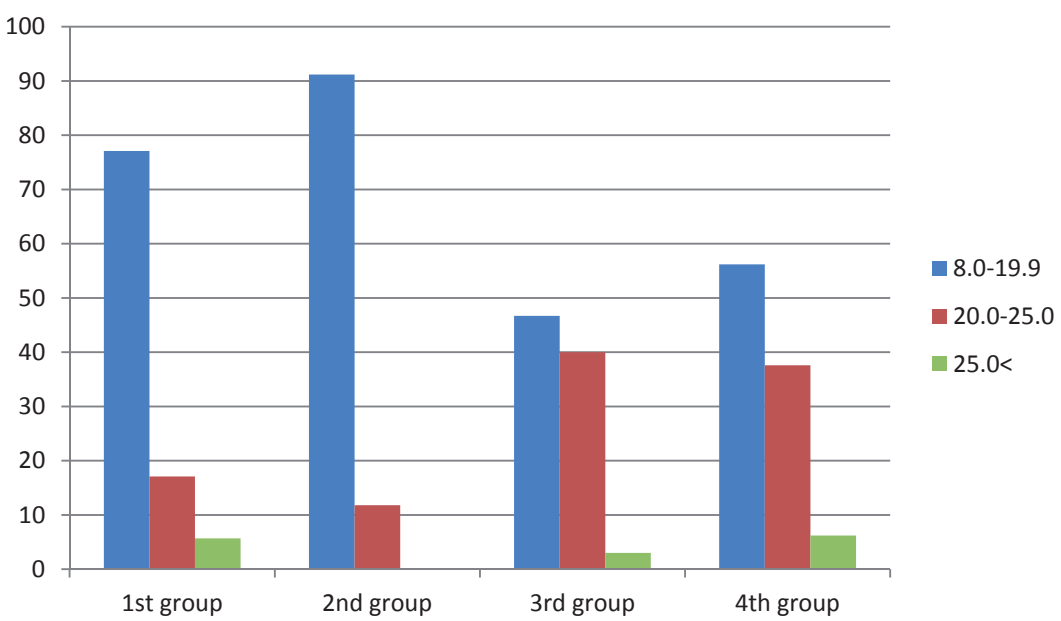

Figure 2. Body fat range distribution in the experimental groups of cadets of NDA.

The analysis of anthropometric characteristics in the 3rd group for 5 th year cadets (2014) allows us to calculate the Body Mass Index, its average value in the 3 rd experimental group was $26.4 \pm 0.8$ (Figure 1 ). The number of cadets with the BMI value corresponding to the standard interval (18.0-24.9) of healthy is more than two times less - $26.7 \%$ than in the 1 st and 2 nd experimental groups. We pay attention to the increasing the number of the cadets $(53.5 \%)$ with the BMI value including the interval of overweight (25.0-29.9). More than two times higher is the number of cadets (18.7\%) who had the BMI above 30 . The assessment of the data of body fat revealed that for $46.7 \%$ of the 5 th year cadets (2014) corresponded to the healthy range, but in the 3rd experimental group there are fat problems for $40.0 \%$ cadets and the obese problems for $13.3 \%$ of cadets (Figure 2). The analysis the data of the questionnaire concerning the musculoskeletal symptoms has shown that for $88 \%$ cadets of the 5 th year $(n=17,2014)$ exist pain symptoms that are related to the musculoskeletal pathology. The main problematic regions were: the lower back (52.9\%), then the knee region (58.8\%) and the shoulder region (47.1\%). The isolated pain in the lower back region pointed out by $13.3 \%$ of cadets, but the combined pain disorders are had by $13.3 \%$ of cadets, only some of the cadets have combined pain in the lower back region, and the hip joint and $13.3 \%$ of the cadets have the combined pain in the lower back region and the knee joint. The combined pain in three regions (lower back, hip joint and knee joint) is a problem for $6.6 \%$ ( Figure 3 ). The assessment of the morphology and functional characteristics of the foot for the 5 th year cadets (the experimental group No3) revealed 
that $26.7 \%$ of respondents have deviation from the standard foot characteristics for one foot, and for the other respondents (73.3\%) foot pathology for both feet is expressed. There were no cadets with morphological characteristics of the foot in that experimental group. Dysfunctions of the foot are connected to the musculoskeletal disorders and initiate the musculoskeletal pathology.

The assessment of anthropometric data in the 4th group for the 4th year cadets (2014) has shown that the average value of the Body Mass Index was 25.3 \pm 0.5 . Half of the cadets (50\%) have the BMI value that corresponded to the standard level (18.0-24.9) - the norm and the other part of cadets of the 4th experimental group (50\%) expressed overweight problems (Figure 1). The evaluation of the body fat range has shown that for $56.2 \%$ of the 4 th year cadets (2014) corresponded to the healthy range, but in the 4th experimental group there are fat problems for $37.6 \%$ cadets and the obese problems for $6.2 \%$ of cadets (Figure 2).

The main problematic regions were: the lower back (50.0\%), then the knee region (75\%) and the shoulder region (25\%). The isolated pain in the lower back region was pointed out by $6.2 \%$ of cadets, but combined pain disorders are had by $37.5 \%$ of cadets, only some of the cadets have combined pain in the lower back region knee joint (Figure 3).

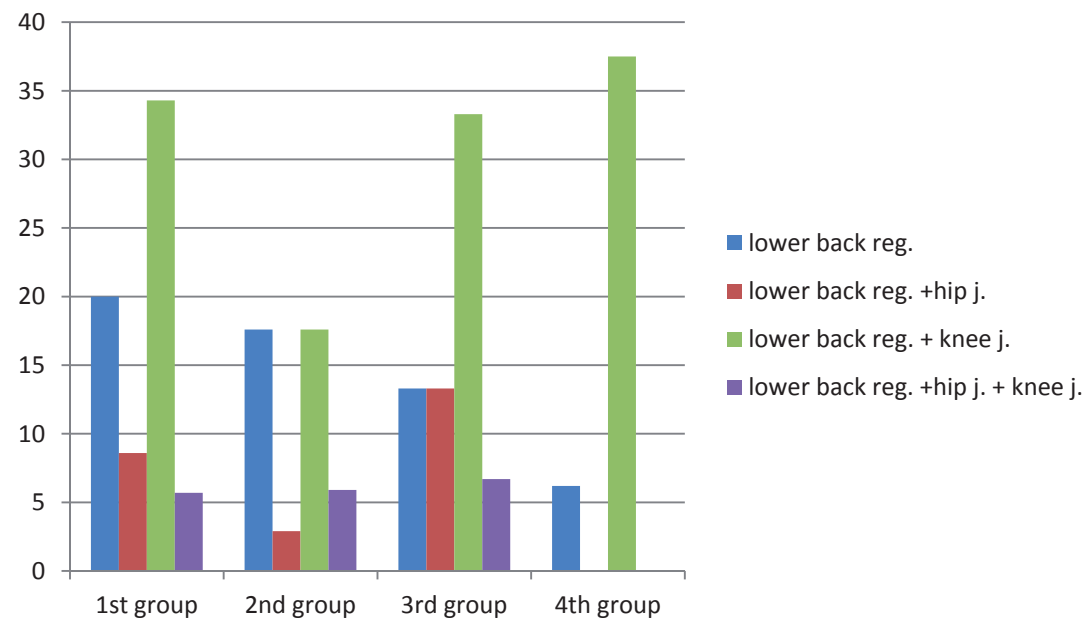

Figure 3. Pain symptoms of musculoskeletal disorders distribution in the experimental groups of cadets of NDA. 


\section{CONCLUSION}

1. The analysis of the average value of the Body Mass Index did not reveal differences between the respondents of experimental groups. But at the same time the assessment of the range of the Body Mass Index has shown that the number of the individuals that related to the overweight problems increased with the age. The number of cadets with overweight problems in the 1 st and the 2nd experimental group was 34.3 (1st group) and 35.3 (2nd group), but in the $3 \mathrm{rd}$ and the 4 th experimental group the number of the individuals with the overweight problems increased about 1.5 times $-53.5 \%$ (3rd group) and 50\% (4th group).

2. The evaluation of the body fat range revealed that the healthy body fat range is had by $77.1 \%$ (1st group) and $91.2 \%$ (2nd group), but in the 3rd and the 4 th experimental groups the number of individuals with the healthy assessment of body fat range decreased about two times $-46.7 \%$ (3rd group) and $56.2 \%$ (4th group)

3. Military training conditions in combination with the intrinsic (individual) factors form the risk for musculoskeletal disorders. Respondents in all experimental groups pointed out pain in the lower back region, the hip joint region, the knee joint region, but the largest problem is combined with the pain for the lower back and the knee joint region that was expressed by respondents in all the experiment groups from 17.6 to the $37.5 \%$.

4. The analysis of anthropometric parameters and the evaluation of the data with the Questionnaire for the Analysis Musculoskeletal Symptoms may be important to provide preventive measures to reduce the risk of musculoskeletal disorders linked to the specific job and the treatment at the early stage where the combination of the extrinsic factors condition and intrinsic factors is present.

\section{REFERENCES}

1. Berkowitz S.M., Feuerstein M., Lopez M.S., Peck C.A. Jr. (1999). Occupational back disability in US Army personnel. Military Medicine, 164,6,4, $12-8$.

2. Glad D., Skillgate E., Holm L.W. (2012). The occurrence and severity of musculoskeletal disorders in Swedish military personnel during peacekeeping operations in Afghanistan. Eur Spine J, 21,4, 739-44.

3. Feuerstein M., Berkowitz S., Peck C.A. Jr. (1997). Musculoskeletal-Related Disability in US Army Personnel: Prevalence, Gender, and Military Occupational Specialties. Med J. of Occupational \& Environmental Medicine, 39, 1, 68-78. 
4. Gallagher D., Heymsfield S.B., Heo M., Jebb S.A., Murgatroyd P.R., Sakamoto Y. (2000). Healthy percentage body fat ranges: an approach for developing guidelines based on body mass index. Am J Clin Nutr, 72,3, 694-701.

5. Heir T., Eide G. (1997). Injury proneness in infantry conscripts undergoing a physical training programme: smokeless tobacco use, higher age, and low level of physical fitness are risk factors. Scand J Med Sci Sports, 7,5,304-11.

6. Heir T., Eide G. (1996). Age, body composition, aerobic fitness and health condition as risk factors for musculoskeletal injuries in conscripts. Scand J Med Sci Sports, 6,4, 222-7.

7. Kuorinka, I., Jonsson, B., Kilbom, A., Vinterberg, H., Biering-Sørensen, F., Andersson, G., Jørgensen, K. (1987). Standardised Nordic questionnaires for the analysis of musculoskeletal symptoms. Applied Ergonomics, 18,3, 233-237.

8. Leggat, P.A., Smith D.R. (2007). Military training and musculoskeletal disorders. Journal of Musculoskeletal Pain, 15,2, 25-32.

9. Parkkari J., Taanila H., Suni J., Mattila V.M., Ohrankämmen O., Vuorinen P., Kannus P., Pihlajamäki H. (2011). Neuromuscular training with injury prevention counselling to decrease the risk of acute musculoskeletal injury in young men during military service: a population-based, randomised study. BMC Medicine, 9:35. (http://www.biomedcentral.com/1741-7051/8/35).

10. Rosendal L., Langberg H., Skov-Jensen A., Kjaer M. (2003). Incidence of injury and physical performance adapting during military training. Clin J Sport Med, 13, 157-163.

11. Taanila H., Suni J., Pihlajamäki H., Mattila V.M., Ohrankämmen O., Vuorinen P., Parkkari J. (2010). Aetiology and risk factors of musculoskeletal disorders in physically active conscripts: a follow-up study in Finnish Defence Forces. BMC Musculoskelet Disorders, 11, 146. (http://www.biomecentral. com/1741-7-51/9/35).

12. Taanila H., Suni J., Pihlajamäki H., Mattila V.M, Ohrankämmen O., Vuorinen P., Parkkari J. (2009). Musculoskeletal disorders in physically active conscripts: one-year follow-up study in the Finnish Defence Forces. BMC Musculoskeletal Disorders, 10, 89. (http://www.biomedcentraal.com/1741-24474/10/89).

\section{Address for correspondence:}

Liana Plavina

National Defence Academy of Latvia

LV-1014, Ezermalas str. 8, Riga, Latvia

E-mail: lianap@inbox.lv 